\title{
The Galerki Approach for Finite Elements of Field Functions: The Case of Buckling in GRP
}

\section{Chukwutoo Christopher Ihueze}

Department of Industrial/Production Engineering, Nnamdi Azikiwe University Awka, Nigeria

Contacts: ihuezechukwutoo@yahoo.com, Phone: 08037065761

\begin{abstract}
This paper used the equation of the deflected axis of a beam to present procedures for solving one-dimensional functions that can be expressed in the form of Poisson equation. The equation of the deflected axis of a beam was solved for deflection for GRP composite component by Finite Element Method (FEM) using integrated FEM-Galerki approach to derive the finite elements equations. The critical stress of GRP structure at the onset of structural instability was computed as $14.162 \mathrm{MPa}$ using Euler relation while the maximum bending moment, a subject in the equation of the deflected axis of a beam of structure was also estimated with classical relation. The equation of the deflected axis of the beam is then solved as a one dimensional Poisson equation following FEM-Galerki approach for deriving element equation. The maximum optimum deflection a measure of maximum instability occurring around the mid span of element of structure was estimated. Also the finite element predicted results were compared with analytical results and the finite element results captured the general trend of the analytical results.
\end{abstract}

Keywords: finite element, buckling deflection, GRP, instability, field function.

\section{INTRODUCTION}

In many applications, such as machine tools transmissions and large structures, deflection considerations may just be as important as the maximum stress induced. Serious misalignments and interferences caused by excessive deflection could cause a machine to malfunction long before it fractured due to stress [1]. Deflection values are also a useful tool in analyzing average strength in structures since the two properties is inversely proportional. 
The stiffness value of a design takes account of the loading exerted and is given as:

$$
\text { Stiffness }=\frac{\text { Force }}{\text { Deflection }}
$$

It is useful to note that stiffness is directly proportional to strength and thus may be used to compare average stress values of designs. Optimum buckling response model of GRP composites has been established experimentally and numerically leading to establishing some mechanical properties of GRP composites that gives designers an insight to buckling strength of GRP composites [2].

A major objective of this work is to predict optimum buckling deflection by solving the equation of the deflected axis of a beam by finite element method. Finite element method has the advantage of evaluating deflection at various nodal or mesh points of a composite beam highlighting on the critical sections of the beam. The involvement of natural boundary conditions in finite element modeling is a panacea for solution of initial value or boundary value problem aiding the evaluation of intermediate values $[3,4]$.

Instability analysis is very important because some structures may fail before reaching their elastic limit. These days thin sections are needed to introduce some desired flexibility in components. The Finite difference method (FDM) has been used to develop finite difference model of failure response of GRP composites to optimize the compressive strength of GRP composites in compressive or buckling environment [5].

The solid mechanics properties of material such as modulus of elasticity, slenderness ratio, radius of gyration, moment and moment of inertia of section were reviewed and applied to determine the finite element property matrix. During composition of GRP for buckling environment, the natural boundary conditions i.e. slopes at beginning and end of beam are expected to be less than unity so that the equation of the deflected axis of a beam could be applied in modeling [6].

Buckling has become more of a problem in recent years since the use of high strength material requires less material for load support, structures and components have become generally more slender and buckle - prone. This trend has continued throughout the technological history. A thin walled structure is made from a material whose thickness is mush less than other structural dimension as found in plate assemblies, common hot and cold - formed structural sections, tubes and cylinders, and many bridge and aerospace structures.

The two fundamental steps in finite element analysis (FEA) are preprocessing and postprocessing involving idealization, discretization and solution as presented in Figure 1 and

Figure 2. The finite element modeling involves the abstraction of a physical system by creating discrete finite sub regions within a continuum to obtain a finite element geometric model. This is used to obtain a finite element mathematical or symbolic model by passing approximating or curve fitting polynomial/function through the established element nodal points. This procedure is well developed in $[2,4]$. Disretization in finite element method gives room to identify critical 
location for point of first failure. Composites in general have random material properties as many materials are involved as constituents during the formative stage.

\section{THEORETICAL BACKGROUND ON COMPRESSIVE FAILURE OF BEAM.}

A horizontal beam situated on the $\mathrm{x}$ axis of an xy coordinate system and supported at both ends bends under the influence of axial compressive loads as depicted in Figure 1. The deflection curve of the beam often called the elastic curve is also shown in Figure 1

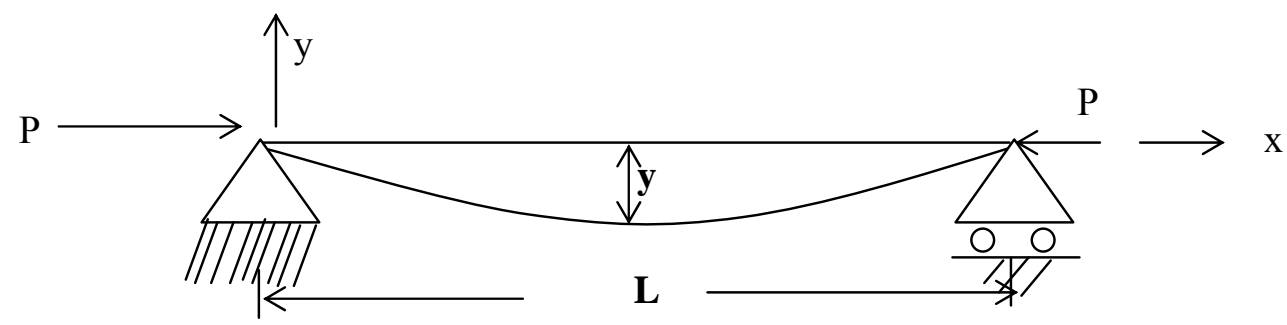

Figure 1. Beam compressive loading and deflected beam axis.

Following Figure 1, Euler 1774 expressed the minimum buckling model of engineering member subjected to axial compression within its materials elastic limit provided that the greatest dimension is more than 4 to 6 times its least cross sectional size as

$$
\mathrm{P}=\frac{\Pi^{2} \mathrm{EJ}}{\mathrm{L}}
$$

The buckling stress, critical stress, following equation (1) is classically expressed as

$$
\mathrm{Sc}=\frac{\Pi^{2} \mathrm{E}}{\wedge^{2}}
$$

Equation (1) was derived by employing the well known equation of deflected axis of a beam usually expressed as

$$
\text { EJ } \frac{\partial^{2} y}{\partial x^{2}}=M(x)
$$

The maximum compressive stress of a beam subject to axial compression is expressed in [6] as

$$
\mathrm{S}=\frac{\mathrm{P}}{\mathrm{A}}+\frac{\mathrm{Mc}}{\mathrm{J}}
$$

where

$$
\mathrm{E}=\text { modulus of elasticity of material }
$$




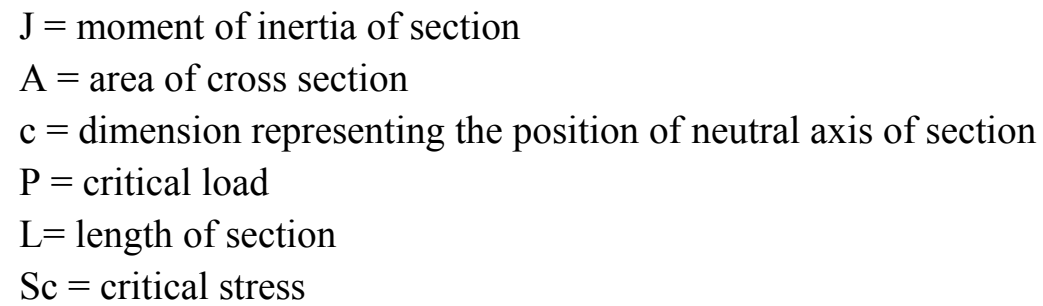

The critical stress of beam under compressive loading is expressed in [7].

Equation (4) shows that when a beam is subjected to axial compression, stress due to axial load and stress due to induced moment are set up. The computing model for moment of inertia and slenderness ratio of section is expressed in [8] as

$$
\mathrm{J}=\mathrm{Ak}^{2}=\frac{\mathrm{bd}^{3}}{3}=\frac{\mathrm{b}}{\sqrt{3}}
$$

and

$$
\wedge=\frac{\mathrm{L}}{\mathrm{k}} \quad, \mathrm{c}=\frac{\text { depth of section }}{2}
$$

where

$$
\begin{aligned}
& \wedge=\text { slenderness ratio. } \\
& k=\text { radius of gyration of section. } \\
& b=\text { breath of section } \\
& d=\text { depth of section. }
\end{aligned}
$$

The maximum compressive strength of GRP composites is $50 \%$ its tensile strength $[9,10,11]$. Also reported in [9] is that the tensile strength of GRP composite is about $303 \mathrm{MPa}$ so that the compressive strength becomes about $152 \mathrm{MPa}$. Equation (4) could then be re-expressed as

$$
152=\frac{\mathrm{P}}{\mathrm{A}}+\frac{\mathrm{Mc}}{\mathrm{J}}
$$

Equation (7) shows that as bending of member decreases the compressive strength becomes due to axial compression alone so that the maximum compressive strength becomes due to axial compression. Equation (4) becomes, by using the result of [2] by [5] and assumption of [9],

$$
154=\frac{\mathrm{P}}{\mathrm{A}} \pm \frac{\mathrm{Mc}}{\mathrm{J}}
$$

From Euler 1774, the critical force Pc $=\mathrm{P}$, so that

$$
\frac{\mathrm{P}}{\mathrm{A}}=\frac{\mathrm{Pc}}{\mathrm{A}}=\frac{\Pi^{2} \mathrm{E}}{\wedge^{2}}
$$


Equation (8) may be re-expressed as

$$
154=\frac{\Pi^{2} \mathrm{E}}{\wedge^{2}} \pm \frac{\mathrm{Mc}}{\mathrm{J}}
$$

The basic properties of materials of structure like modulus of elasticity and moment of inertia of section are found by employing the equation of deflected axis of a beam with some experimentally derived data expressed as

$$
\mathrm{EJ} \frac{\partial^{2} \mathrm{y}}{\partial \mathrm{x}^{2}}=\mathrm{M}(\mathrm{x})
$$

so that by subject of formula

$$
\frac{\partial^{2} y}{\partial x^{2}}=\frac{M(x)}{E J}
$$

By method of weighted residual, equation (11) becomes

$$
R=\frac{\partial^{2} y}{\partial x^{2}}-\frac{M(x)}{E J}
$$

\section{METHODOLOGY}

Finite elements formulation involves discretizing, choice of approximating polynomial, derivation of shape function, interpolation functions, and expression of element equations in terms of interpolation functions. The basic steps of FEM are found in [4, 12]. The Galerki method was used in deriving element and assembly equations while LU-decomposition is used in obtaining solutions. The basic steps used with Galerki method to obtain the finite element results involve:

- Discretization

- Proposing polynomial interpolation within the element, the number of unknown coefficients being equal to the number of nodes defining the topology of the element

- Evaluation of interpolation at each node and equating to the nodal displacement. This gives a set of simultaneous linear equations which will be solved to yield the unknown polynomial coefficients.

- Substitution of expression of coefficients into the original interpolation (approximation polynomial) and the arrangement of terms to yield an expression of the form(shape function)

$$
\mathrm{u}(\mathrm{x})=\mathrm{N}_{1}(\mathrm{x}) \mathrm{y}_{1}+\mathrm{N}_{2}(\mathrm{x}) \mathrm{y}_{2}+\ldots \ldots \ldots \ldots \ldots \ldots
$$


- Substitution of shape function expression into the governing differential equation.

- Solution of the differential equations following Galerki method and application of integration by parts for all nodes

- Expressing element equations

- Assembling of elements equations

- Solution of assembly equations

- Post processing of results

\subsection{Modeling and Computations}

The geometrical and mathematical models of function are reduced to finite element algorithms and the field function of interest is solved at the designated nodes.

\subsubsection{Discretizing composite function into 5 elements}

The field function or region is divided into five solution domains.

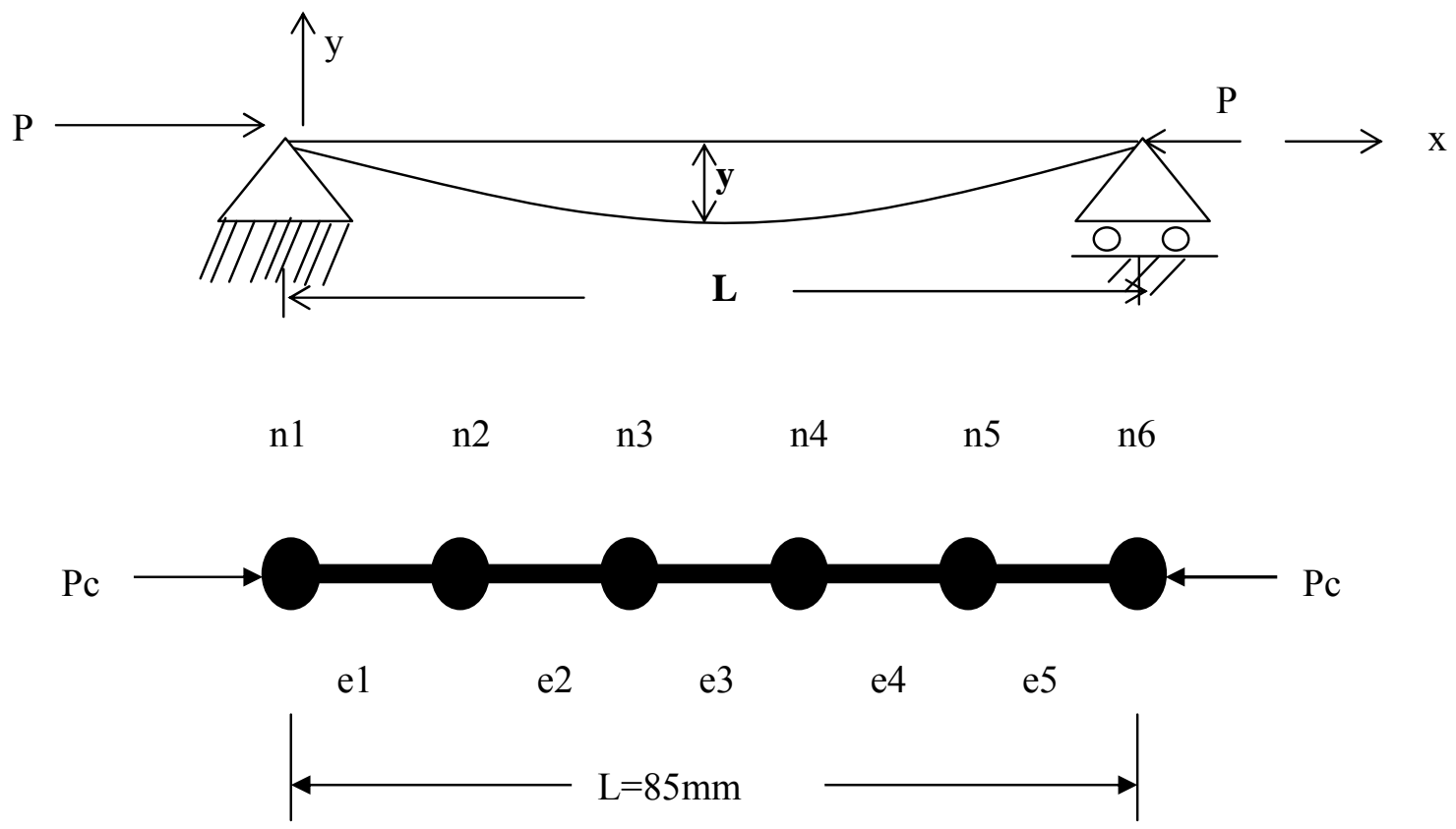

Figure 2. Finite element discrete model, where n, represent node and e, element:

Six nodes-five elements segmentation scheme

\subsubsection{Approximation polynomial, shape function and interpolation function}

The approximation polynomial is chosen as first order linear polynomial as 
and by passing the polynomial through nodes 1 and 2

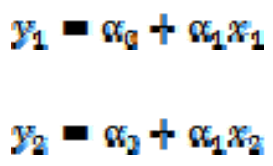

By using equation (15) and equation (16) in matrix form, the polynomial coefficients or shape constants are solved by Cramer's rule as follows

$$
\left[\begin{array}{ll}
1 & x_{1} \\
1 & x_{2}
\end{array}\right]\left[\begin{array}{l}
x_{0} \\
x_{1}
\end{array}\right]=\left[\begin{array}{l}
y_{1} \\
y_{2}
\end{array}\right]
$$

So that the determinant of coefficient matrix becomes

$\Delta=x_{2}-x_{1}$

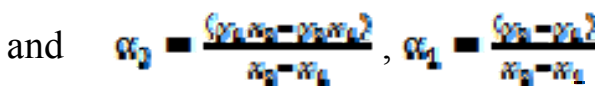

The approximation or shape function then becomes by equation (14)

$y=\frac{\left(y_{1} x_{2}-y_{2} x_{1}\right)}{x_{2}-x_{1}}+\frac{\left(y_{2}-y_{1}\right)}{x_{2}-x_{1}} x$

$y\left(x_{2}-x_{1}\right)=y_{1} x_{2}-y_{2} x_{1}+y_{2} x-y_{1} x$

By grouping of terms,

$$
\begin{aligned}
& y(x)\left(x_{2}-x_{1}\right)-y_{1} x_{2}-y_{1} x+y_{2} x-y_{2} x_{1}-y_{1}\left(x_{2}-x\right)+y_{2}\left(x-x_{1}\right) \\
& y(x)=y_{1} \frac{w_{n}}{w_{2}-x_{2}}+y_{2} \frac{w}{w_{2}-w_{4}} \\
& y=N_{1} y_{1}+N_{2} y_{2}
\end{aligned}
$$

Equation (17) or equation (18) is called approximation or shape function while $\mathrm{N}_{1}, \mathrm{~N}_{2}$ are called interpolation functions.

By differentiating functions with respect to $\mathrm{x}$ using equation (18)

$$
\frac{g n}{g x}=\frac{d w_{4}}{d n} y_{1}+\frac{d N_{n}}{d x} y_{2}
$$


From (4)

$$
\begin{aligned}
& \mathrm{N}_{1}=\frac{w_{n}-w_{2}}{w_{2}-w_{k}} N_{2}=\frac{w-w_{4}}{w_{2}-w_{4}} \\
& \underset{d x}{d N_{6}}=\frac{1}{x_{2}-x_{L}{ }^{2}} d \mathrm{~N}_{\mathrm{a}}=\frac{1}{x_{2}-x_{L}} \\
& \frac{g_{Y}}{\gamma_{r}}=\frac{1}{w_{2}-v_{u}}\left(-y_{1}+y_{2}\right)
\end{aligned}
$$

\subsection{Galerki Method for Eelement Equation: The Method of Weighted Residuals (MWR)}

By employing the equation of a deflected axis of a beam as

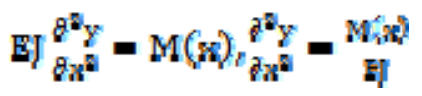

By passing equation (18) through equation (22),

$$
\frac{2^{2}}{2 x^{2}}=\frac{N(x)}{n}
$$

Since equation (18) does not give the exact value of the function, equation (23) can be expressed as

$R=\frac{g^{2} \mathrm{y}}{g x^{2}}-\frac{\mathrm{M}(\mathrm{g})}{\mathrm{Z}}$

MWR suggests that

$\int_{\mathrm{D}} \mathrm{RW} / \mathrm{dD}=0, \mathrm{Q}=1,2_{\nu} \ldots \mathrm{m} \mathrm{m}_{\gamma} \mathrm{D}=$ solution domain

$\mathrm{Wi}=$ linearly independent weighting functions

By finite element procedure, $\mathrm{Wi}=\mathrm{Ni}$ so that equation (24a) becomes

$\int_{\mathrm{D}} \mathrm{RNIdD}=0,1=\mathbb{1}_{i} \mathrm{z}_{i} \mathrm{n} \mathrm{m}_{l}$

By using equation (15) in the Galerki method equation of equation (25), the one dimensional compression equation of equation (22) becomes

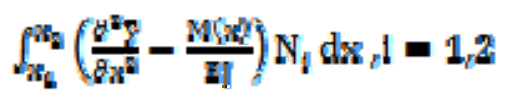


Equation (26) can be expressed as

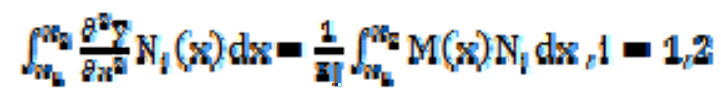

Integration by parts is used to simplify the L.H.S of equation (27)

$\int_{a}^{b} u d v=u v-\int_{a}^{b} v d u$

so that by Choosing

$\mathrm{N}_{1}(\mathrm{x})=\mathrm{u}_{v} \frac{\mathrm{g}^{2} \mathrm{z}}{\mathrm{x}^{2}} \mathrm{dx}=\mathrm{dy}$

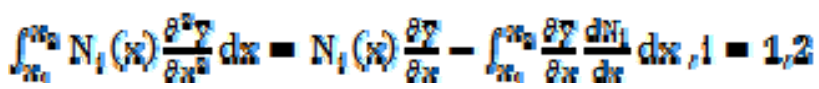

By evaluating the terms in equation (29)

For $\mathbf{i}=1$

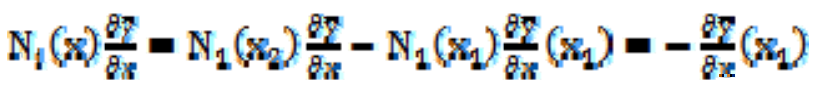

For $\mathbf{i}=2$

$\mathrm{N}_{2}(\mathrm{x}) \frac{\mathrm{g}}{\mathrm{g}}=-\frac{\partial \mathrm{z}}{g_{x}}\left(\mathrm{x}_{2}\right)$

Substituting equation (30) and equation (31) in equation (29) and then in equation (27),

For $\mathbf{i}=\mathbf{1}$

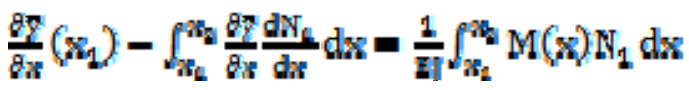

For $\mathbf{i}=2$

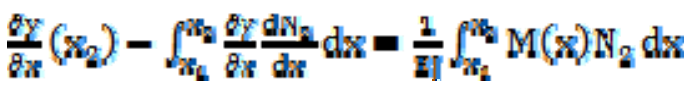

But $\mathrm{x}_{1}=0, \mathrm{x}_{2}=17$

By evaluating equation (32) and equation (33) the element 1 equations are established.

$\frac{d N_{1}}{d x}=-\frac{1}{x_{g}-w_{1}}, \frac{d N_{R}}{d x}=\frac{1}{w_{g}-w_{1}}$ 
$\frac{\partial y}{\partial x}=\frac{1}{x_{2}-x_{1}}\left(-y_{1}+y_{2}\right)$

By putting values in (32) for $\mathrm{i}=1$

$-\frac{g y}{\partial x}\left(x_{1}\right)+\frac{1}{y_{2}-x_{1} y^{2}} \int_{x_{6}}^{x_{2}}\left(-y_{1}+y_{2}\right) d x=-\frac{g y}{\partial y}\left(x_{1}\right)+\frac{1}{2 g}-17 y_{1}+y_{2}$

Also

$\frac{M(x)}{E I} \int_{w_{L}} \mathrm{~N}_{1}(\mathrm{x}) \mathrm{d} \mathrm{d}=17 \frac{M(x)}{2 E I}$, so that

$\frac{1}{17}\left(-y_{1}+y_{2}\right)=\frac{g y}{g x}\left(x_{1}\right)+17 \frac{M\left(x_{1}\right)}{2 z i}$

Similarly by putting values in equation (33) for $i=2$

$$
-\frac{1}{17}\left(-y_{1}+y_{2}\right)=-\frac{g}{g n}\left(x_{2}\right)+17 \frac{M(x)}{2 E}
$$

Equation (34) and equation (35) form the system of equations for element 1and may be expressed in matrix form as

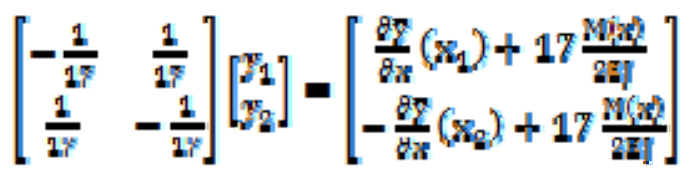

\subsection{Geometrical Consideration and Estimation of Important Material Data}

Geometrical factors like bending moment, moment of inertia, radius of gyration slenderness ratio and critical stress are computed to aid solution of equation (36) and presented in Table 1.

Table 1. Estimation of Important Material Data.

\begin{tabular}{|l|l|l|}
\hline Property & Formula & Results \\
\hline Moment of Inertia, $\mathrm{J}$ & $\mathrm{bd}^{3} / 3$ & $1.5625 \times 10^{-10} \mathrm{~m}^{4}$ \\
\hline Area of cross section $\mathrm{A}$ & $\mathrm{bd}, \mathrm{b}=30 \mathrm{~mm}, \mathrm{~d}=2.5 \mathrm{~mm}$ & $7.5 \times 10^{-5} \mathrm{~m}^{2}$ \\
\hline Radius of Gyration, $\mathrm{k}$ & $(\mathrm{J} / \mathrm{A})^{1 / 2}$ & $1.44 \mathrm{~mm}$ \\
\hline Slenderness Ratio, $\wedge$ & $\mathrm{L} / \mathrm{k}, \mathrm{L}=85 \mathrm{~mm}$ & 59 \\
\hline Modulus of Elasticity & Experimentally found & $5 \mathrm{GPa}$ \\
\hline Bending moment, $\mathrm{M}(\mathrm{x})$ & $\mathrm{P} / \mathrm{A}+\mathrm{Mc} / \mathrm{J}$, Smax $=154 \mathrm{MPa}$ & $17.47975 \mathrm{NM}$ \\
\hline Critical Stress & $\Pi^{2} \mathrm{E} / \wedge^{2}$ & $14.162 \mathrm{MPa}$ \\
\hline
\end{tabular}




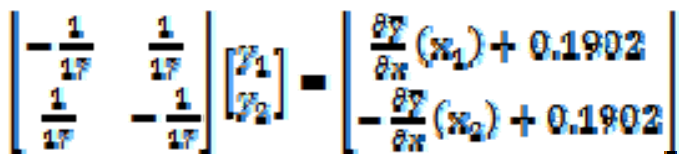

\subsubsection{Element topology definitions}

The element topology assists in the computation and assembly of element equations. It takes the form of proper assignment of numbers to element nodes.

Table 2. Node Numbering and Element Topology Definitions.

\begin{tabular}{|l|l|l|l|}
\hline $\begin{array}{l}\text { Element } \\
\text { number e }\end{array}$ & $\begin{array}{l}\text { Local node } \\
\text { numbering }\end{array}$ & $\begin{array}{l}\text { Global node } \\
\text { numbering }\end{array}$ & $\begin{array}{l}\text { Active degrees o } \\
\text { freedom as } \\
\text { element e is } \\
\text { assembled }\end{array}$ \\
\hline & 1,2 & 1,2 & $\mathrm{y}_{1}, \mathrm{y}_{2}$ \\
\hline & 1,2 & 2,3 & $\mathrm{y}_{2}, \mathrm{y}_{3}$ \\
\hline & 1,2 & 3,4 & $\mathrm{y}_{3}, \mathrm{y}_{4}$ \\
\hline & 1,2 & 4,5 & $\mathrm{y}_{4}, \mathrm{y}_{5}$ \\
\hline & 1,2 & 5,6 & $\mathrm{y}_{5}, \mathrm{y}_{6}$ \\
\hline
\end{tabular}

By applying element topology definition and concept of nodal continuity other elements equations are written and assembled.

\section{For element 2}

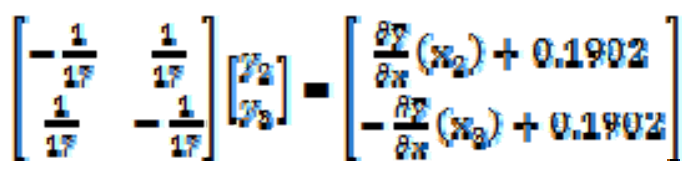

For element 3

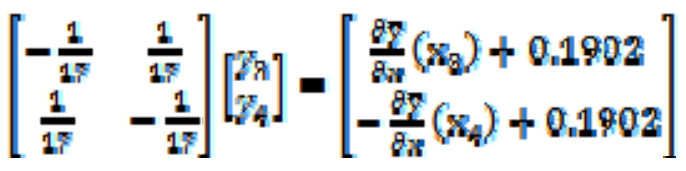

For element 4

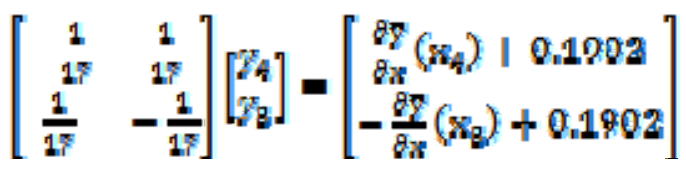




\section{For element 5}

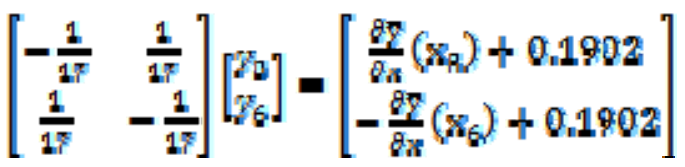

Where

$$
\begin{array}{lll}
\mathrm{y}_{1} & = & \text { Active degree of freedom representing deflection at node } 1 \\
\mathrm{y}_{2} & = & \text { Active degree of freedom representing deflection at node } 2 \\
\mathrm{y}_{3} & = & \text { Active degree of freedom representing deflection at node } 3 \\
\mathrm{y}_{4} & = & \text { Active degree of freedom representing deflection at node } 4 \\
\mathrm{y}_{5} & = & \text { Active degree of freedom representing deflection at node } 5 \\
\mathrm{y}_{6} & = & \text { Active degree of freedom representing deflection at node } 6 \\
\mathrm{x}_{1} & = & \text { first nodal position } \\
\mathrm{x}_{2} & = & \text { second nodal position } \\
\mathrm{x}_{3} & = & \text { third nodal position } \\
\mathrm{x}_{4} & = & \text { fourth nodal position } \\
\mathrm{x}_{5} & = & \text { fifth nodal position } \\
\mathrm{x}_{6} & = & \text { sixth nodal position }
\end{array}
$$

\subsection{Assembling and Derivation of Elements Assembly Equation}

The respective element equations are established from elements topology descriptions and are added randomly into the initialized assembly matrices describing the property matrix, boundary influence matrix and external effects matrix as follows. The assembling is done element equations after element equations with respect to elements degrees of freedom or variables present in the element equations, until the final element equation is assembled to obtain the assembly equation as in equation (43)

\subsubsection{Initialized assembly zero matrix}

The initial matrix to aid assembly of elements matrixes can be expressed as

$$
\left[\begin{array}{llllll}
0 & 0 & 0 & 0 & 0 & 0 \\
0 & 0 & 0 & 0 & 0 & 0 \\
0 & 0 & 0 & 0 & 0 & 0 \\
0 & 0 & 0 & 0 & 0 & 0 \\
0 & 0 & 0 & 0 & 0 & 0 \\
0 & 0 & 0 & 0 & 0 & 0
\end{array}\right]\left[\begin{array}{l}
y_{1} \\
y_{2} \\
y_{3} \\
y_{4} \\
y_{3} \\
y_{6}
\end{array}\right]=\left[\begin{array}{l}
0 \\
0 \\
0 \\
0 \\
0 \\
0
\end{array}\right]
$$

By random addition of matrixes of equations ((37) - (41)) into equation (42) the assembly equation is obtained after all the $2 \times 2$ element matrixes of equations ((37) - (41)) are transformed to $6 \times 6$ matrixes. 


\subsubsection{Transformation of element matrixes}

The transformed element matrixes are added to the initialized zero matrix of (42) by random matrix addition. The element matrixes are transformed as follows:

For element 1

$\left[\begin{array}{cccccc}0.0588 & 0.0588 & 0.0000 & 0.0000 & 0.0000 & 0.8000 \\ 0.0588 & -0.0588 & 0.0000 & 0.0000 & 0.0000 & 0.0000 \\ 0.0000 & 0.0000 & 0.0000 & 0.0000 & 0.0000 & 0.0000 \\ 0.0000 & 0.0000 & 0.0000 & 0.0000 & 0.0000 & 0.0000 \\ 0.0000 & 0.0000 & 0.0000 & 0.0000 & 0.0000 & 0.0000 \\ 0.0000 & 0.0000 & 0.0000 & 0.0000 & 0.0000 & 0.0000\end{array}\right]\left[\begin{array}{l}y_{1} \\ y_{2} \\ y_{8} \\ y_{4} \\ y_{8} \\ y_{k}\end{array}\right]=$

$$
\left[\begin{array}{c}
\frac{\partial y}{\partial x}\left(\mathrm{n}_{1}\right)+0.1902 \\
-\frac{\partial y}{\partial x}\left(\mathrm{n}_{2}\right)+0.1902 \\
0.0000 \\
0.0000 \\
0.0000 \\
0.0000
\end{array}\right]
$$

For element 2

$\left[\begin{array}{cccccc}0.0000 & 0.0000 & 0.0000 & 0.0000 & 0.0000 & 0.0000 \\ 0.0000 & -0.0988 & 0.0588 & 0.0000 & 0.0000 & 0.0000 \\ 0.0000 & 0.0588 & -0.0588 & 0.0000 & 0.0000 & 0.0000 \\ 0.0000 & 0.0000 & 0.0000 & 0.0000 & 0.0000 & 0.0000 \\ 0.0000 & 0.0000 & 0.0000 & 0.0000 & 0.0000 & 0.0000 \\ 0.0000 & 0.0000 & 0.0000 & 0.0000 & 0.0000 & 0.0000\end{array}\right]\left[\begin{array}{l}y_{1} \\ y_{2} \\ y_{8} \\ y_{4} \\ y_{8} \\ y_{4}\end{array}\right]=$

$$
\left[\begin{array}{c}
0.0000 \\
\frac{\partial y}{\partial x}\left(\mathrm{n}_{2}\right)+0.1902 \\
-\frac{\partial g}{\partial x}\left(\mathrm{n}_{2}\right)+0.1902 \\
0.0000 \\
0.0000 \\
0.0000
\end{array}\right]
$$

For element 3

$\left[\begin{array}{cccccc}0.0000 & 0.0000 & 0.0000 & 0.0000 & 0.0000 & 0.0000 \\ 0.0000 & 0.0000 & 0.0000 & 0.0000 & 0.0000 & 0.0000 \\ 0.0000 & 0.0000 & -0.0588 & 0.0588 & 0.0000 & 0.0000 \\ 0.0000 & 0.0000 & 0.0588 & -0.0588 & 0.0000 & 0.0000 \\ 0.0000 & 0.0000 & 0.0000 & 0.0000 & 0.0000 & 0.0000 \\ 0.0000 & 0.0000 & 0.0000 & 0.0000 & 0.0000 & 0.0000\end{array}\right]\left[\begin{array}{l}y_{1} \\ y_{8} \\ y_{8} \\ y_{4} \\ y_{8} \\ y_{k}\end{array}\right]=$




$$
\left[\begin{array}{c}
0.0000 \\
0.0000 \\
\frac{\partial g}{\partial x}\left(N_{0}\right)+0.1902 \\
-\frac{\partial g}{\partial x}\left(N_{4}\right)+0.1902 \\
0.0000 \\
0.0000
\end{array}\right]
$$

For element 4

$$
\begin{aligned}
& {\left[\begin{array}{cccccc}
0.0000 & 0.000 & 0.0000 & 0.0000 & 0.0000 & 0.0000 \\
0.0000 & 0.0000 & 0.0000 & 0.0000 & 0.0000 & 0.0000 \\
0.0000 & 0.0000 & 0.0000 & 0.0000 & 0.0000 & 0.0000 \\
0.0000 & 0.000 & 0.0000 & 0.0580 & 0.0588 & 0.0000 \\
0.0000 & 0.0000 & 0.0000 & 0.0588 & -0.0588 & 0.0000 \\
0.0000 & 0.0000 & 0.0000 & 0.0000 & 0.0000 & 0.0000
\end{array}\right]\left[\begin{array}{l}
x_{4} \\
y_{2} \\
y_{8} \\
y_{4} \\
y_{8} \\
y_{4}
\end{array}\right]=} \\
& {\left[\begin{array}{c}
0.0000 \\
0.0000 \\
0.0000 \\
\frac{\partial g}{\partial x}\left(x_{4}\right)+0.1902 \\
-\frac{\partial g}{\partial x}\left(n_{g}\right)+0.1902 \\
0.0000
\end{array}\right]}
\end{aligned}
$$

\begin{tabular}{|c|c|c|c|c|c|c|}
\hline$[0,0000$ & 0.0000 & 0,0000 & ๑.0000 & 0.0000 & 0.9000 & $1 y_{1}^{y_{1}}$ \\
\hline 0.0000 & 0.0000 & 0.0000 & 0.0000 & 0.0000 & 0,0000 & $y_{2}$ \\
\hline 0.0000 & 0.0000 & 0.0000 & ๑.Q000 & 0.0000 & 0.0000 & $y_{g}$ \\
\hline 0,0000 & 00000 & 0.0000 & 0,0000 & 0.0000 & 0,0000 & $y_{4}$ \\
\hline 0.0000 & 00000 & 0.0000 & -0.0588 & 0.0588 & 0,0000 & $y_{0}$ \\
\hline 0.0000 & 0.0000 & 0.0000 & 0.0000 & 0.0980 & -09म8 & \\
\hline
\end{tabular}

For element 5

$$
\left[\begin{array}{c}
0,0000 \\
0,0000 \\
0,0000 \\
0.0000 \\
\frac{\partial y}{\partial x_{g}}\left(N_{5}\right)+0.1902 \\
-\frac{\partial y}{\partial x}\left(n_{6}\right)+0.1902
\end{array}\right]
$$


So that by the addition of the above transformed matrixes the assembly system is obtained as

$\left[\begin{array}{cccccc}-0.0588 & 0.0588 & 0.0000 & 0.0000 & 0.0000 & 0.0000 \\ 0.0588 & 0.1176 & 0.0588 & 0.0000 & 0.0000 & 0.0000 \\ 0.0000 & 0.0000 & -0.1176 & 0.0588 & 0.0000 & 0.0000 \\ 0.0000 & 0.0588 & 0.0588 & -0.1176 & 0.0588 & 0.0000 \\ 0.0000 & 0.0000 & 0.0000 & 0.0988 & -0.1176 & 0.0588 \\ 0.0000 & 0.0000 & 0.0000 & 0.0000 & 0.0588 & -0.0588\end{array}\right]\left[\begin{array}{l}y_{1} \\ y_{2} \\ y_{8} \\ y_{4} \\ y_{8} \\ y_{4}\end{array}\right]=$

$$
\left[\begin{array}{c}
\frac{\partial g}{\partial x}\left(n_{1}\right)+0.1902 \\
0.3804 \\
0.2804 \\
0.3804 \\
\frac{\partial g}{\partial x}\left(\mathrm{n}_{6}\right)+0.1902 \\
-\frac{\partial g}{\partial x}\left(\mathrm{n}_{6}\right)+0.1902
\end{array}\right]
$$

By substituting the natural boundary conditions $\mathrm{y}_{1}=0, \mathrm{y}_{6}=0$ in equation (43) the following system of equations is obtained

$$
\begin{aligned}
& 0.0588 \mathrm{y}_{2}=\frac{87}{8 \mathrm{x}}\left(\mathrm{x}_{1}\right)+0.1902 \\
& -0.1176 \mathrm{y}_{2}-0.1176 \mathrm{y}_{3}=0.3804 \\
& 0.0588 \mathrm{y}_{2}-0.1176 \mathrm{y}_{3}+0.0588 \mathrm{y}_{4}=0.3804 \\
& 0.0588 \mathrm{y}_{4}-0.1176 \mathrm{y}_{4}+0.0588 \mathrm{y}_{5}=0.3804 \\
& 0.0588 \mathrm{y}_{4}-0.1176 \mathrm{y}_{5}=0.3804 \\
& 0.0588 \mathrm{y}_{5}=\frac{8 \eta}{\partial \mathrm{a}}\left(\mathrm{x}_{6}\right)+0.1902
\end{aligned}
$$

Equations (44)-(49) can be expressed in matrix form and solved by LU-Decomposition method to obtain,

$$
\begin{aligned}
& \mathrm{y}_{2}=-12.9388 \mathrm{~mm}, \mathrm{y}_{3}=19.4082, \mathrm{y}_{4}=19.4082, \mathrm{y}_{5}=-12.9388 \mathrm{~mm} \\
& \frac{8 \mathrm{~g}}{8 \mathrm{~g}}\left(\mathrm{x}_{1}\right)=-0.9510, \frac{8 \mathrm{~g}}{\mathrm{~g}_{\mathrm{m}}}\left(\mathrm{x}_{2}\right)=-0.9510
\end{aligned}
$$

\subsection{Discretizing to 10 Elements}

This involves dividing the region into domains or segmentation of the region.

By following similar procedures as in five elements model, and using Figure 3, the following nodal deflections are obtained: 


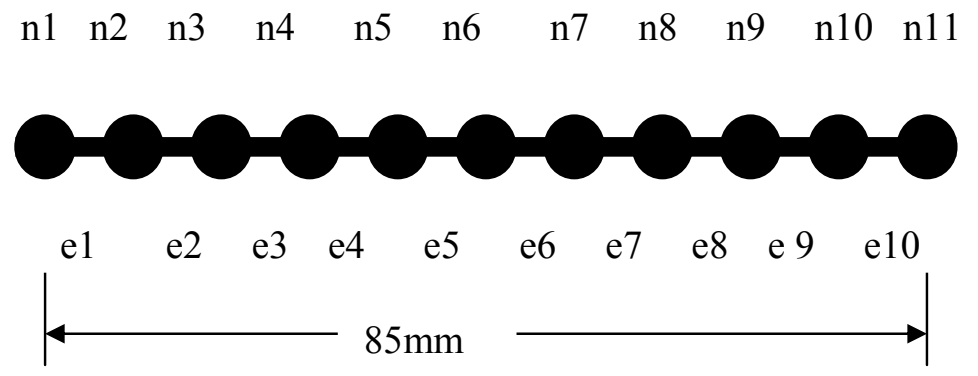

Figure 3. Finite element Discrete Model: Eleven nodes-ten elements segmentation scheme.

For element 1

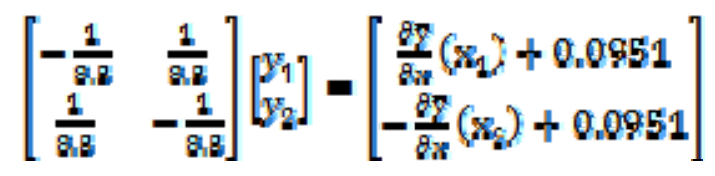

\section{For element 2}

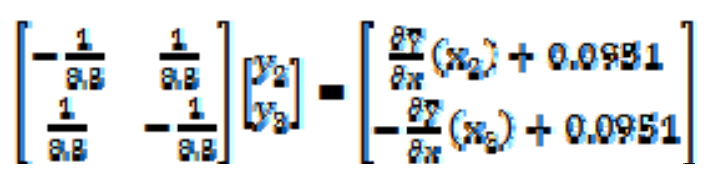

For element 3

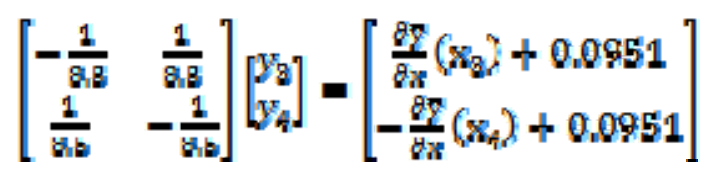

\section{For element 4}

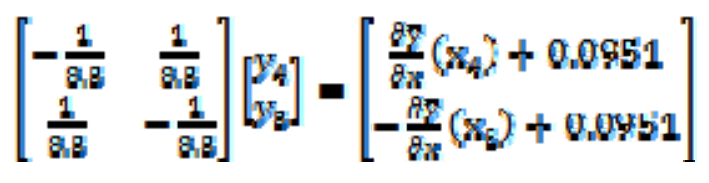

\section{For element 5}

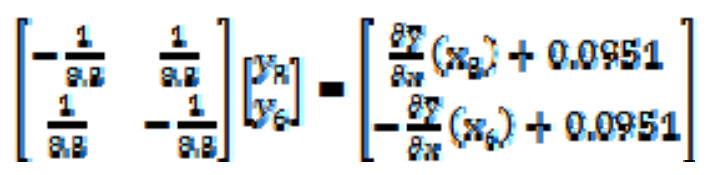


For element 6

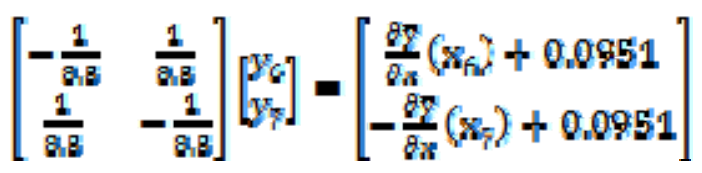

For element 7

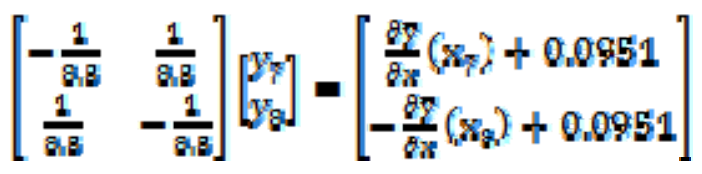

For element 8

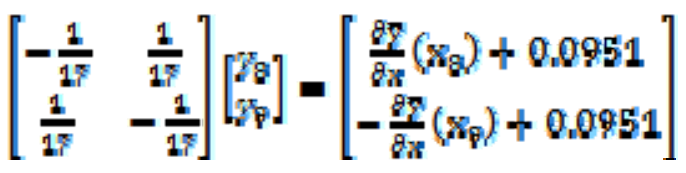

For element 9

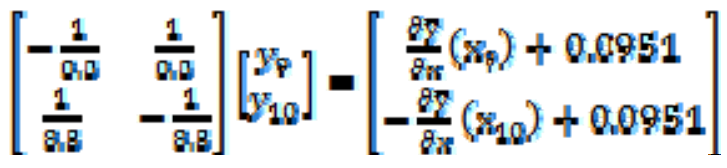

For element 10

$\left[\begin{array}{cc}-\frac{1}{g B} & \frac{1}{a s} \\ \frac{1}{a s} & -\frac{1}{a s}\end{array}\right]\left[\begin{array}{l}y_{10} \\ y_{11}\end{array}\right]=\left[\begin{array}{c}\frac{g z}{g x}\left(x_{10}\right)+0.0981 \\ -\frac{g z}{g x}\left(x_{11}\right)+0.0951\end{array}\right]$

The ten elements equations are assembled and solved to obtain the following results:

$\mathrm{y}_{2}=-7.221813 \mathrm{~mm}, \mathrm{y}_{3}=-12.83242 \mathrm{~mm}, \mathrm{y}_{4}=-16.83659 \mathrm{~mm}, \mathrm{y}_{5}=-19.23774 \mathrm{~mm}$

$\mathrm{y}_{6}=-20.03789 \mathrm{~mm}, \mathrm{y}_{7}=-19.23774 \mathrm{~mm}, \mathrm{y}_{8}=-16.83659 \mathrm{~mm}, \mathrm{y}_{9}=-12.83242 \mathrm{~mm}$

$\mathrm{y}_{10}=-7.221813 \mathrm{~mm}, \mathrm{x}_{1}=\frac{8 \mathrm{~g}}{g_{\mathrm{x}}}\left(\mathrm{x}_{1}\right)=-0.9443852, \mathrm{x}_{11}=\frac{8 \mathrm{~g}}{g_{\mathrm{n}}}\left(\mathrm{x}_{11}\right)=-.9443852$

\subsection{Analytical Computations of Element Nodal Deflection}

Classical reports of $[6,7]$ gave the analytical equation of deflected axis of beam as

$$
\mathrm{y}_{\mathrm{a}}=\mathrm{a} \frac{\operatorname{Sin} \pi \mathrm{x}}{\mathrm{L}}
$$

where 
$\mathrm{y}_{\mathrm{a}}=$ Deflection at a point,

$\mathrm{x}=$ position of reference $=$ length of beam,

$\mathrm{a}=$ maximum deflection

By using, $a=y_{6}=-20.0379 m m$ estimated by FEM, $L=85 \mathrm{~mm}$

$\mathrm{x}=$ various nodal positions as in Figure 2 in equation (60) the analytical solutions are computed and presented as in Table 4

Table 4. Computations for Maximum Deflection.

\begin{tabular}{|r|r|r|r|}
\hline Nodes & \multicolumn{1}{l|}{$\mathrm{X}(\mathrm{mm})$} & \multicolumn{1}{l|}{ FEM } & \multicolumn{1}{l|}{ Analytical } \\
\cline { 3 - 4 } & & \multicolumn{1}{l}{$\mathrm{y}(\mathrm{mm})$} & \multicolumn{2}{l|}{$\mathrm{y}_{\mathrm{a}}(\mathrm{mm})$} \\
\hline & 0.00 & 0.00 & 0.00 \\
\hline & 8.50 & -7.22 & -5.59 \\
\hline & 17.00 & -12.8 & -10.73 \\
\hline & 25.50 & -16.8 & -15.03 \\
\hline & 34.00 & -19.2 & -18.13 \\
\hline & 42.50 & -20.0 & -19.79 \\
\hline & 34.00 & -19.2 & -18.13 \\
\hline & 25.50 & -16.8 & -15.03 \\
\hline & 17.00 & -12.8 & -10.73 \\
\hline & 8.50 & -7.22 & -5.59 \\
\hline & 0.00 & 0.00 & 0.00 \\
\hline
\end{tabular}

Excel graphic package was used with Table 4 data to produce the graphics of Figure 4 and presented below.

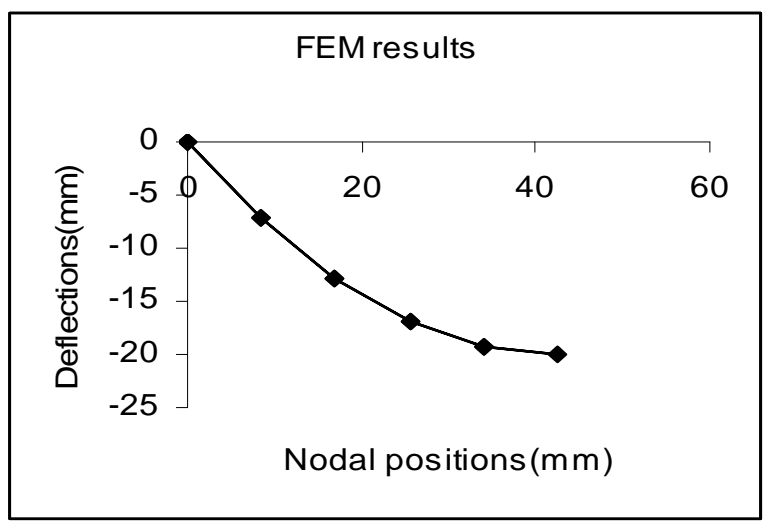

Figure 4a. Graphical Depiction of FEM Results. 


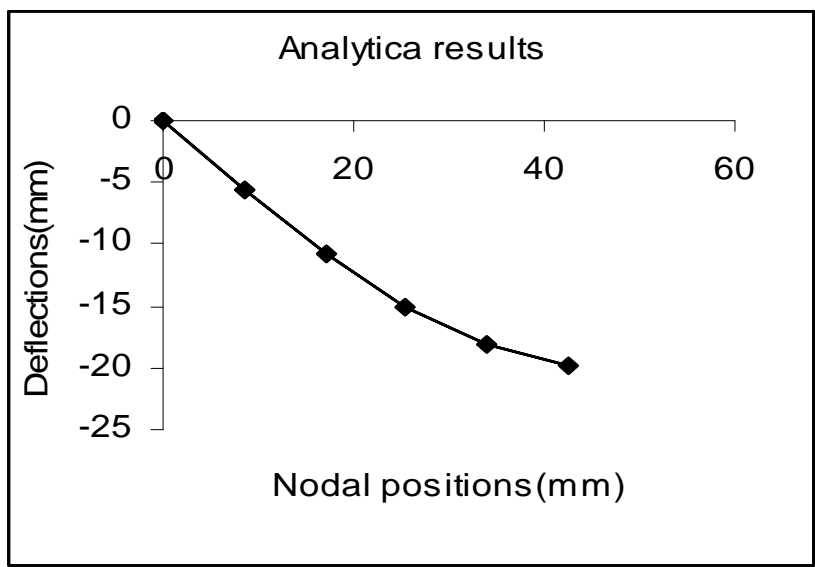

Figure 4b. Graphical Depiction of Analytical Results.

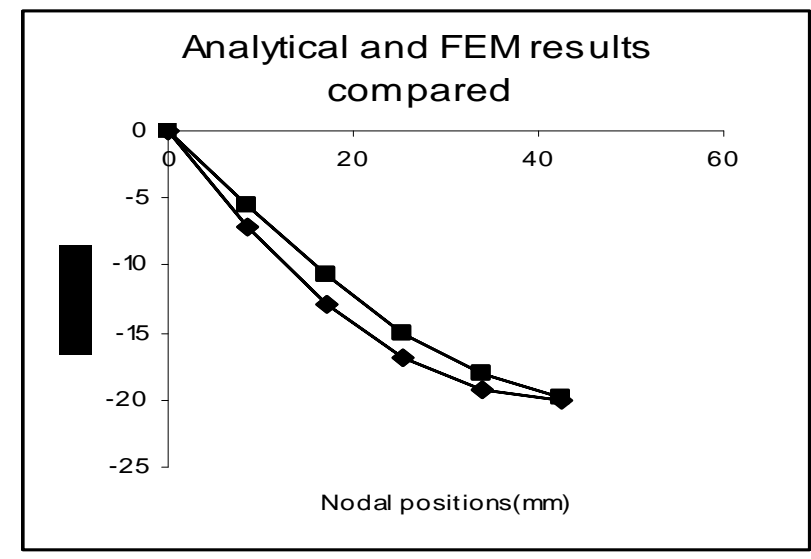

Figure 4c. Graphical Depiction of Analytical and FEM Results.

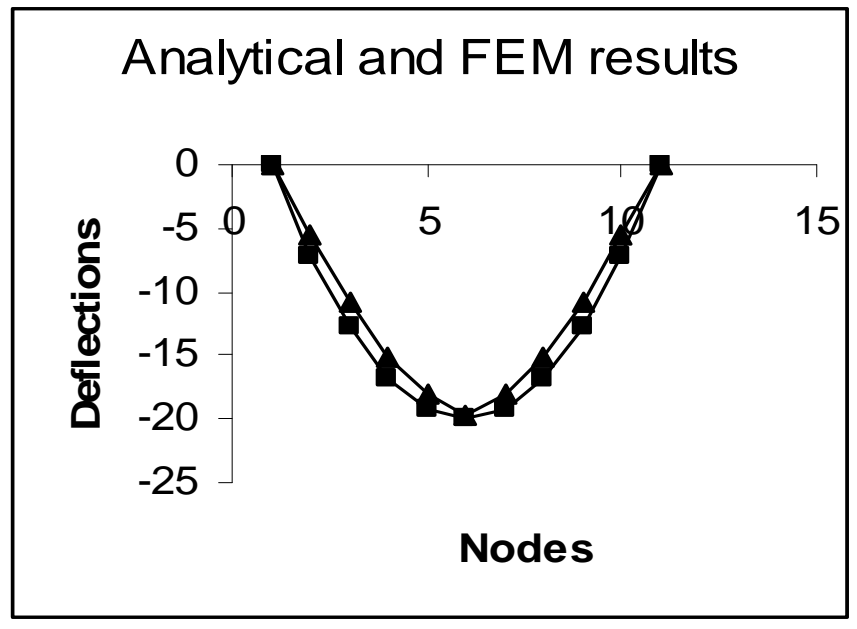

Figure 4d. Graphical Depiction of Position of Optimum Deflection. 


\section{DISCUSSIONS ON RESULTS}

Both results of FEM with five elements and FEM with 10 elements capture the general trend of analytical solution (see Figure 4a-d). Also the result of FEM with five and ten elements show that as more elements are introduced better result that capture the general trend is obtained but the computational efforts are maximized.

Establishment of elements equations of FEM by Galerki approximations is a worthy method since the results of assemblage equations are unique and capture the general trend of analytical solution (see Figure $4 \mathrm{c}$ and d). The graphics of Figures show that the optima for both solutions occurred at the middle of the section with optimum deflection of about $20 \mathrm{~mm}$. The graphics also show parabolic response of deflection of a stressed composite beam whose governing equation could be represented as

$$
\frac{\partial^{2} y}{\partial x^{2}}=f(x)
$$

This is analogous to one- dimensional Poisson equation relation. The finite element method used Galerki approach to derive elements equations. These equations were assembled and solved by LU-decomposition to obtain deflections at various nodes of composite. Classical relation was also used to estimate the deflection. The maximum deflection was estimated to be $-20.0379 \mathrm{~mm}$ by FEM.

In many applications, such as machine tools transmissions and large structures, deflection considerations may just be as important as the maximum stress induced. Serious misalignments and interferences caused by excessive deflection could cause a machine to malfunction long before it fractured due to stress. Deflection values are also a useful tool in analyzing average strength in structures since the two properties is inversely proportional.

The stiffness value of a design takes account of the loading exerted and are given as

$$
\text { Stiffness }=\frac{\text { Force }}{\text { Deflection }}
$$

It is useful to note that stiffness is directly proportional to strength and thus may be used to compare average stress values of designs. Also the values of deflection of Table 4 show that the stiffness and strength of the beam decreases towards the mid span of the beam.

\section{CONCLUSION}

Establishment of elements equations of FEM by FEM-Galerki approximations is a worthy method since the results of assemblage equations are unique and captured the general trend of analytical solution. Both analytic and FEM results show parabolic response of a deflected beam with optimum around mid span of the beam and optimum maximum deflection of $20 \mathrm{~mm}$. The 
maximum deflection, a measure of optimum instability for GRP composites is therefore evaluated by this study as $20 \mathrm{~mm}$.

\section{REFERENCES}

[1] Hawkes, B. and Abinett, R., (1985). The Engineering Design Process, Pitman Publishing. p101.

[2] Ihueze, C.C., (2005).Optimum Buckling Response Model of GRP Composites, Ph.D Thesis, University of Nigeria. p111.

[3] Chapra, S.C and Canale, R.P., (1998). Numerical Methods for Engineers, McGraw-Hill Publishers, $3^{\text {rd }}$ edition, Boston, N.Y. p853.

[4] Astley, R.J., (1992). Finite Elements in Solids and Structures, Chapman and Hall Publishers, UK. p154.

[5] Enetanya, A.N. and Ihueze, C. C., (2008). Computational Approaches for Strengths of GRP Composites. Journal of Engineering and Applied Sciences, vol.4 No.1 and 2. P62.

[6] Black, P.H. and Adams, O.E., (1981).Machine Design. McGraw-Hill International Book Company, Tokyo. p41.

[7] Benham, P.P. and Warnock, F.V., (1981). Mechanics of Solids and Structures. Pitman Books, Toronto. p257.

[8] Beer, F. P. and Johnston, B., (1977). Vector Mechanics for Engineers (Statics), $3^{\text {rd }}$ edition. McGraw-Hill Book Company, New York. p354.

[9] Koshal, D., (1998). Manufacturing Engineers Reference Book, Butterworth Heinemann Publisher. p102.

[10] Rosen, B.W., (1965). Mechanics of Composite Strengthening: Fibre Composite Materials, American Society of Metals, Chapter 3.

[11] Kyriakides, S., Perry, E.J., and Liechti, K.M., (1994). Instability and failure of fibre composites in compressive, ASME Journal of Applied Mechanics, Vol. 47, No. 6, S 262 $-266$.

[12] Zienkiewicz, O.C., (1977). The Finite Element Method: Basic Formulation and Linear Problems, 3rd ed., vol.1, McGraw-Hill, London. p228-301. 